AperTO - Archivio Istituzionale Open Access dell'Università di Torino

\title{
Application of DIC analysis method to the study of failure initiation in gypsum rocks
}

\section{This is a pre print version of the following article:}

Original Citation:

\section{Availability:}

This version is available http://hdl.handle.net/2318/1690090

since 2019-05-16T18:00:37Z

Published version:

DOI:10.1680/jgele.18.00156

Terms of use:

Open Access

Anyone can freely access the full text of works made available as "Open Access". Works made available under a Creative Commons license can be used according to the terms and conditions of said license. Use of all other works requires consent of the right holder (author or publisher) if not exempted from copyright protection by the applicable law. 


\title{
Application of DIC analysis method to the study of failure initiation in gypsum rocks.
}

Chiara Caselle, - orcid: 0000-0002-3081-1555

Dr Gessica Umili - orcid: 0000-0002-2448-6020

Dr Sabrina Bonetto - orcid: 0000-0002-6579-1419

Prof Anna Maria Ferrero - orcid: 0000-0001-8422-6303

Department of Earth Sciences - DST, Università degli Studi di Torino, Torino, 10125, Italy

Correspondence to: Chiara Caselle (chiara.caselle@unito.it) - Department of Earth Science, University of Turin, Via Valperga Caluso 35, 10125 Turin, +39 0116705325

Words: 2066

Figures: 10

\begin{abstract}
The measure of local strains of geomaterials under the application of an external load is an important issue in the study of mechanical properties of rocks. The application of image analysis methods (i.e. Digital Image Correlation analysis) offers the possibility to have pointwise measures of local strains on the entire surface of the samples. Strain contributions in the different areas of the samples can be highlighted and diversified.

We tested this methodology on gypsum rock. Image analysis was applied by means of NCORR, an open source 2D Digital Image Correlation Matlab software. The processing of consecutive images acquired during the execution of Uniaxial Compression Tests allows for the identification of strain distributions and concentrations. The test was repeated for different angles of orientation of the anisotropy.

If properly calibrated, the method may be used to highlight the influence of textural features of the rock materials, such as, in this case, the anisotropy, on the mechanical behaviour. Features as the way of localization of the strain, the load thresholds that lead to the opening of the first microcracks and the way they reorganize to create the failure surface may be deeply investigated.
\end{abstract}

Keywords: Gypsum, Cracks initiation, DIC, Image Analysis 


\section{Introduction}

Over the past two decades different research groups applied visual analysis of image sequences to understand crack initiation and propagation in loaded gypsum samples (e.g Bobet \& Einstein, 1998; Sagong \& Bobet, 2002; Wong \& Einstein, 2009). This kind of qualitative analysis has been used to classify crack coalescence patterns: the subsequent need for a quantitative estimation of the stressstrain curve of the samples has made Digital Image Correlation (DIC), commonly used in mechanical engineering, quite popular in rock tests. DIC is a robust non-contact technique for measuring the relative displacements of points between a reference image and a subsequent one, shot from the same position during a test on a sample of a certain material (Peters \& Ranson, 1982; Chu et al., 1985; Vendroux \& Knauss, 1998; Blaber et al., 2015).

In rock mechanics research field many attempts to apply DIC technique during loading tests were made, e.g. Ferrero \& Migliazza (2009) on marl subjected to uniaxial compression tests, Nguyen et al. (2011) on tuff subjected to plane-strain compression tests, Zhang et al. (2012) on sandstone under indentation, Stirling et al. (2013) on sandstone subjected to Brazilian tests and Yang et al. (2015) on granite subjected to uniaxial traction tests, Guy et al. (2018) to identify rock toughness of fractures in clay-rich rocks.

The open-source, freely available 2D subset-based DIC software package called Ncorr (Blaber et al., 2015) is a complete, updated, efficient and flexible code: the authors chose to use it for processing images of uniaxially loaded samples of gypsum; the resulting stress-displacement and stress-strain curves are compared to those measured by the load equipment; moreover, the influence of the anisotropy orientation with respect to the sample face is investigated.

\section{Material and geological framework}

Laboratory tests have been performed on prismatic samples of microcrystalline gypsum in branching selenite facies. The material comes from the Monferrato area (Piedmont, NW Italy) and have been deposed during the final part of the Miocene epoch, during the Messinian Salinity Crisis (Roveri et al. 2008; Dela Pierre et al. 2011). In the Monferrato area, the stratigraphic record of the Salinity Crisis consists of a unit of primary gypsum (PLG - Primary Lower Gypsum Unit) followed by a unit of re-sedimented gypsum (RLG - Resedimented Lower Gypsum Unit). In the area, PLG unit starts with three main layers of macrocrystalline selenitic gypsum, with mean crystal size of $3-5 \mathrm{~cm}$. Each of those layers is about 10-12 m thick. They are followed by a layer of microcrystalline gypsum, with a mean thickness of $10 \mathrm{~m}$, mainly in branching selenite facies. Interbedded marl levels with thickness of 1-2 m divide the gypsum beds. At the top of this succession, whose relevant thickness of gypsum allow a commercial exploitation, the unit presents a reduction of gypsum bodies thickness, with an alternation of gypsum and marl layers with higher frequency.

We focused on microcrystalline gypsum in facies branching selenite, consisting of fine-grained material, with average grain size of $1 \mathrm{~mm}$. They are organized in decimeter-large irregular nodules and lenses of selenite crystals with major axes slightly inclined or horizontally oriented, separated by thin fine-grained carbonate or gypsum laminae (Lugli et al. 2010).

8 prismatic samples were prepared with average sizes of 100x50x50 mm. Upper and lower faces were polished to obtain smooth and parallel planes. Samples were prepared with different orientations of the anisotropy with respect to the polished faces (Figure 1). Due to the irregularity of the anisotropy direction (constituted by the fine-grained laminae), we considered the mean angle and the associated range of variability. 


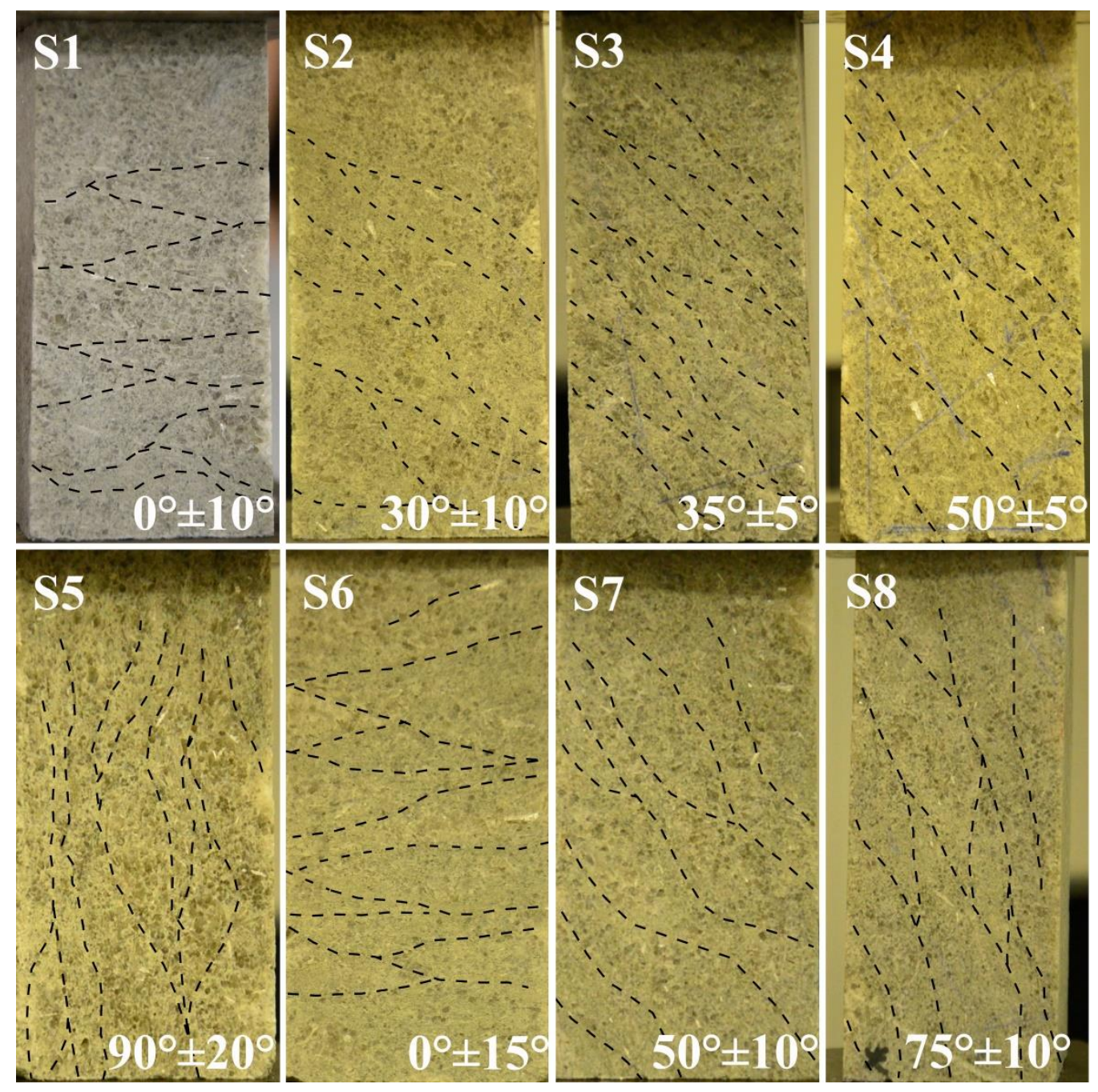

Figure 1 Tested samples and relative range of variability of the anisotropy dip angles.

\section{Methods}

Samples were loaded uniaxially up to the failure with a constant strain rate of $0.06 \mathrm{~mm} / \mathrm{min}(0.03$ $\mathrm{mm} / \mathrm{min}$ for sample 1) in a GDS Instruments Medium Pressure Triaxial Apparatus (MPTA). The same strain rate was maintained also after the peak stress, in order to study the post-peak behaviour. Axial displacements of the entire sample (total displacements) were measured throughout the test with LVDT sensors.

During the test, two cameras (respectively, Nikon, resolution $106 \mathrm{dpi}$, focal length $35 \mathrm{~mm}$ and Sony, resolution $96 \mathrm{dpi}$, focal length $35 \mathrm{~mm}$ ) acquired videos (frame rate: 24 frames/s) of two adjacent and perpendicular faces of the samples (fig. 2). The acquisition of videos was manually started simultaneously with the start of the test.

Ncorr v.1.2.2 software (Blaber et al., 2015), implementing Digital Image Correlation (DIC) algorithms, was used to process frames: we chose to extract from each video a frame every 5 seconds to test the procedure. The software is able to estimate displacement and strain of a sample under deformation through the use of image processing techniques. The method consists in comparing each progressive image with the reference one (shot before the test beginning). The software subdivides the image in small areas (pixel subsets) and verifies their positions with respect to the first image. The result is a grid with displacement data of each subset with respect to the reference image (displacement field). Thanks to the assignment of a scale factor, estimated with a graphical procedure 
as the ratio between a certain length measured on the image (expressed in pixel) and the corresponding length measured in real world (expressed in millimetre), displacement data are converted into the actual unit of measurement of the sample. Strain calculation is then performed using the strain window algorithm proposed by Pan et al. (2009). The method is based on a pointwise local least squares fitting technique. The sample is divided in squared areas containing a finite number of discrete points (i.e., strain calculation window). The strain calculation windows should be small enough so that the displacement distributions inside them can be approximated as planes. With a linear least square minimization, the parameters of those planes can be assessed and used to compute the Green-Lagrangian strains.

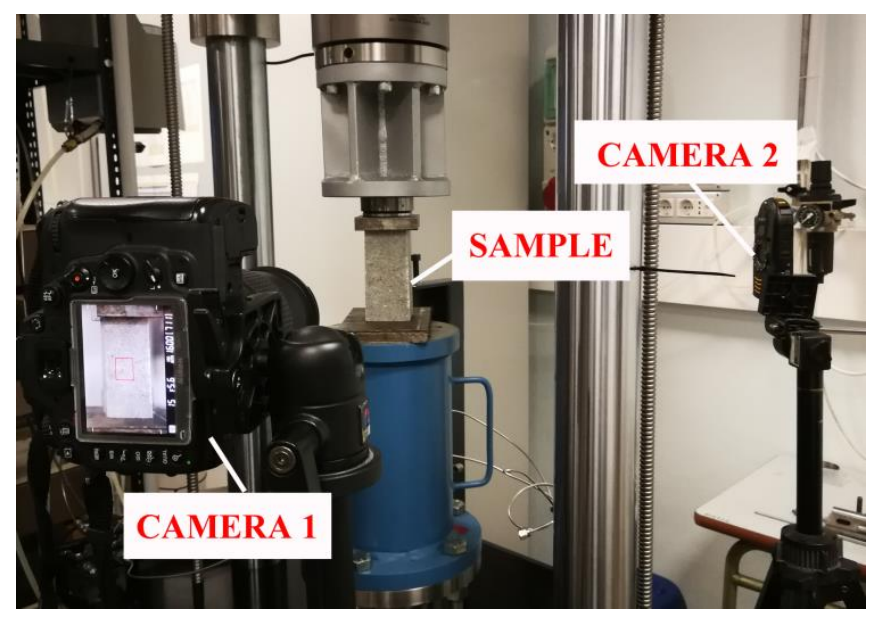

Figure 2 Setting of the uniaxial test equipment and of the two cameras acquiring videos.

\section{Results and Discussion}

Figure 3 shows the uniaxial strength values in function of the anisotropy dip angle ranges. Strengths were calculated from the peak load values measured from the load cell. The impossibility to assign a univocal value of angle, due to the natural irregularity of the anisotropy surfaces, has been represented in the graph through horizontal error bars. Since sample 2 failed during the test preparation in the precharge phase, results refer to a total number of 7 samples.

Results show a clear dependence of strength on the anisotropy orientation: horizontal and vertical anisotropy return the higher strength values, while intermediate angles are associated to a significant strength decrease, suggesting a parabolic trend. Curve in Figure 3 is only qualitative, aiming to underline the trend but not to propose a mathematical relationship, since the quantification of anisotropy dip angle is an interpretation and data are presented as ranges and not as precise numbers. 


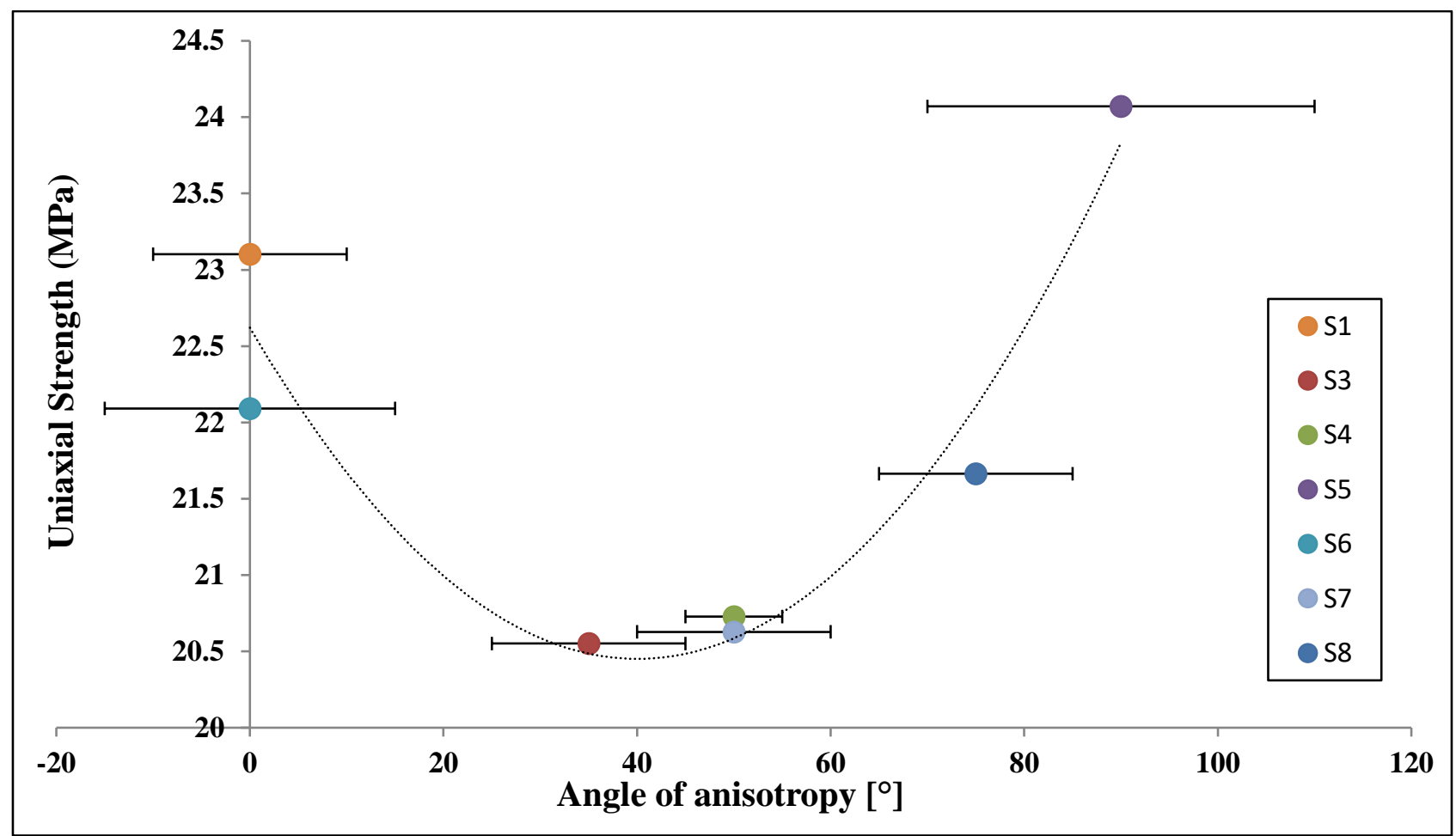

Figure 3 Distribution of uniaxial strength values in function of the dip angle of the anisotropy.

The results of DIC analysis offer the possibility to evaluate displacements and strains in different positions on the sample surface. For instance, figure 4 shows the load-displacement curves of sample 4 along a line straddling the fracture. Each curve is referred to a specific point on the face: displacement values obtained for each frame were associated to the load registered from the load cell at the correspondent time from the beginning of the test. Curves were then compared with the total displacement measured from the machine. The comparison among local axial displacements (from DIC analysis) and total axial displacements (from LVDTs) shows similar trends but a differences in entity, as expected.

Values of displacement from DIC analysis are vectors with concordant versus with the arrows represented in figure $4 \mathrm{~b}$ and $4 \mathrm{c}$. Since the load is applied with a piston from below, the elastic phase shows positive axial displacements (upward), while the lateral displacements are almost zero. Figure 5 , showing the same load-displacement curves in a single graph, helps in reading the data. Before the onset, all the curves of local displacement are equivalent. When the onset is reached, the curves of lateral displacement start to diversify, highlighting the opening of tensional fractures. Indeed, points on the left $(1,2,3)$ move to the left, while points on the right $(4,5,6)$ move to the right. Only after reaching the peak, the curves of axial displacement start to separate, with the upper part, represented by points 4,5 and 6 , showing a negative displacement (downward). This suggests the beginning of a relative sliding movement. 


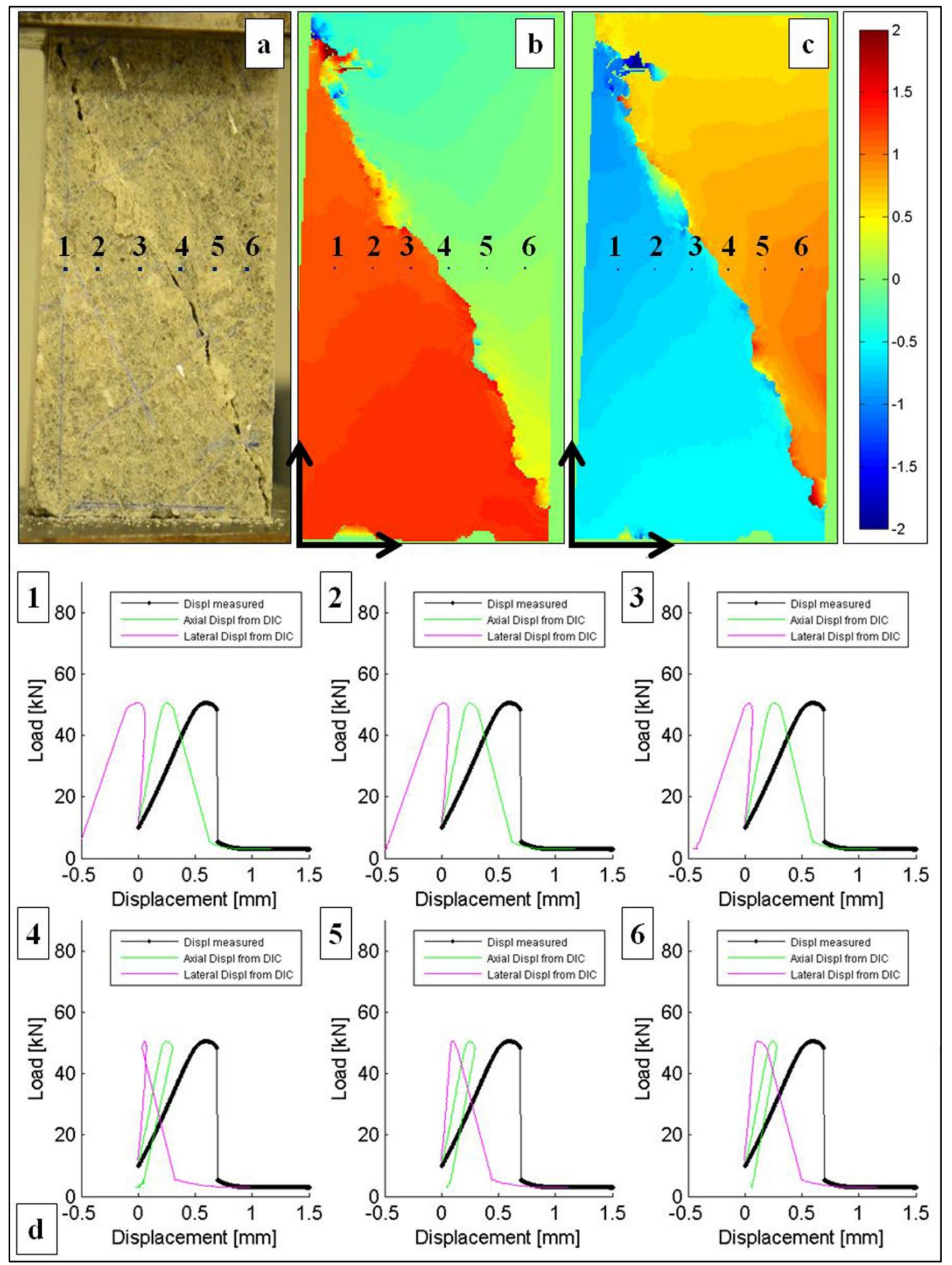

Figure 4 Sample 4 after the test. b. Map of axial displacement at the end of the test. c. Map of lateral displacement at the end of the test. d. Comparison of the load-displacement curve measured from the load system (black curve) and the axial and lateral displacement curves obtained with the DIC analysis for the six points showed in $\mathrm{b}$ and $\mathrm{c}$. Black arrows in figures $\mathrm{b}$ and $\mathrm{c}$ indicate the versus of the positive displacements. 


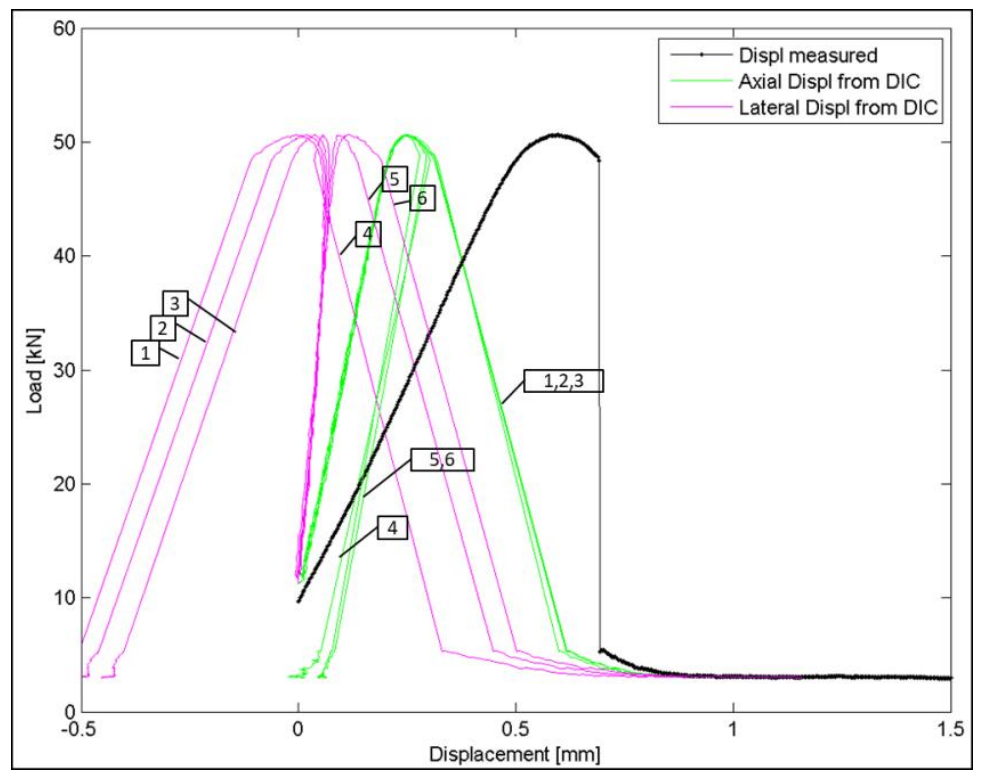

Figure 5 Comparison of load vs displacement curves showed in figure $4 \mathrm{~d}$.

The computation of strains, including a process of differentiation, is highly sensitive to noise. The resulting load-strain curves are, indeed, noisier and less well-defined than the displacement ones.

Figures 6 and 7 show the load vs local strain curves referred to the same horizontal line straddling the fracture analysed in Figure 4.

The linear elastic loading phase, characterized by little local axial and radial strains, is followed by a significant strain acceleration, both in axial and lateral directions, starting from the onset point. No evident difference among the curves is recognized before the peak strength. Nevertheless, after the peak, points 3, 4 and 5 (nearer to the fracture surface) show higher strains, leading to the collapse of the sample. In particular, point 5 , even if in figures $6 \mathrm{~b}$ and $6 \mathrm{c}$ seems to be out from the failure area, shows high deformations before the collapse, suggesting the evolution, during the test, of a larger shear zone than the final failure surface. During the loss of load and the correspondent failure, points 3 and 4 show a sudden increase of strain, while the other points, further from the failure area, show an almost vertical trend. The failure happens, therefore, without any important strain far from the fracture.

After the failure, in almost all the curves, it is possible to recognize a decrease of strain, due to the elastic relaxation of the material. 


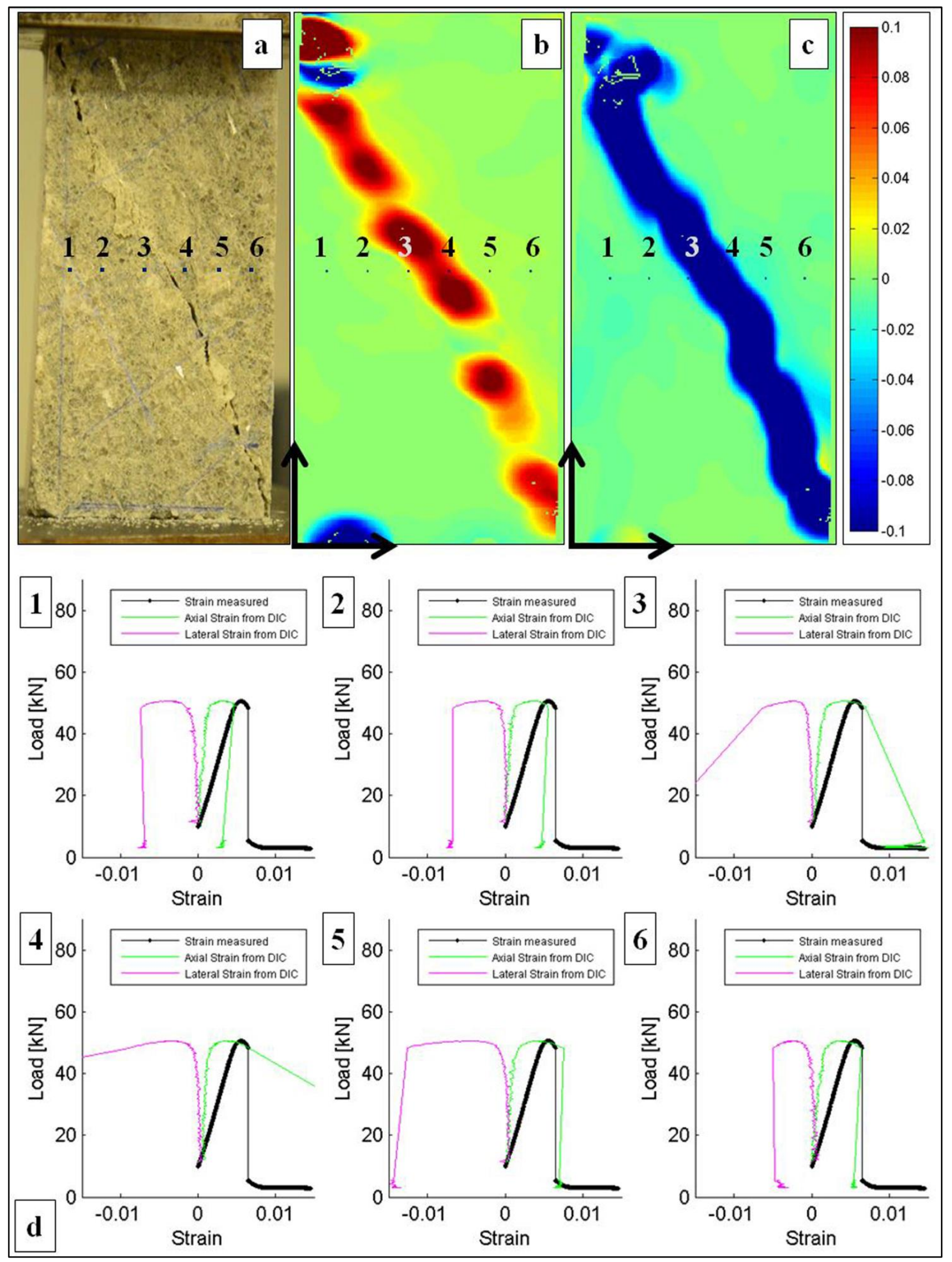

Figure 6 Sample 4 after the test. b. Map of axial strain at the end of the test. c. Map of lateral strain at the end of the test. d. Comparison of the load vs strain curve measured from the load system (black curve) and the axial and lateral strain curves obtained from the DIC analysis for the six points showed in $\mathrm{b}$ and $\mathrm{c}$. Black arrows in figures $\mathrm{b}$ and $\mathrm{c}$ indicate the versus of the positive displacements. 


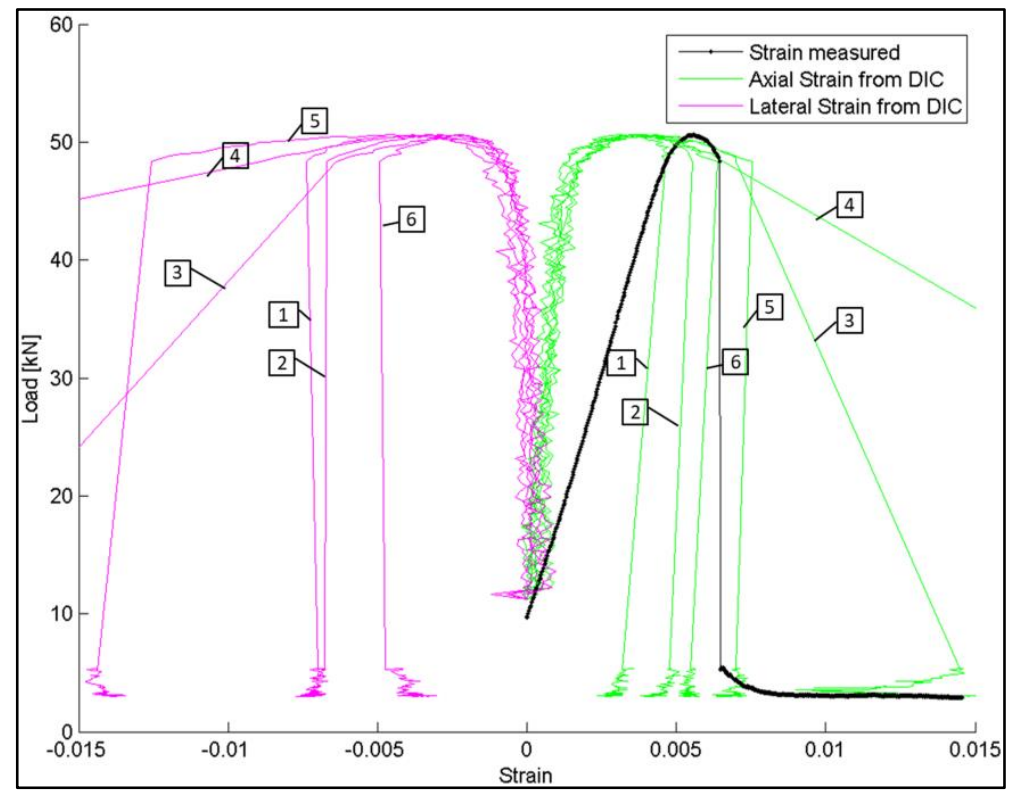

Figure 7 Comparison of load vs strain curves referred to the points in figure $6 \mathrm{~b}$ and $6 \mathrm{c}$.

Similar evidences can be observed from DIC analysis results of all the tested samples. Some differences, however, can be recognized, caused by the influence of the anisotropy direction. For instance, sample 5, with vertical anisotropy, even showing a similar evolution, has lower local strains, both in lateral and axial direction (Figure 8). 


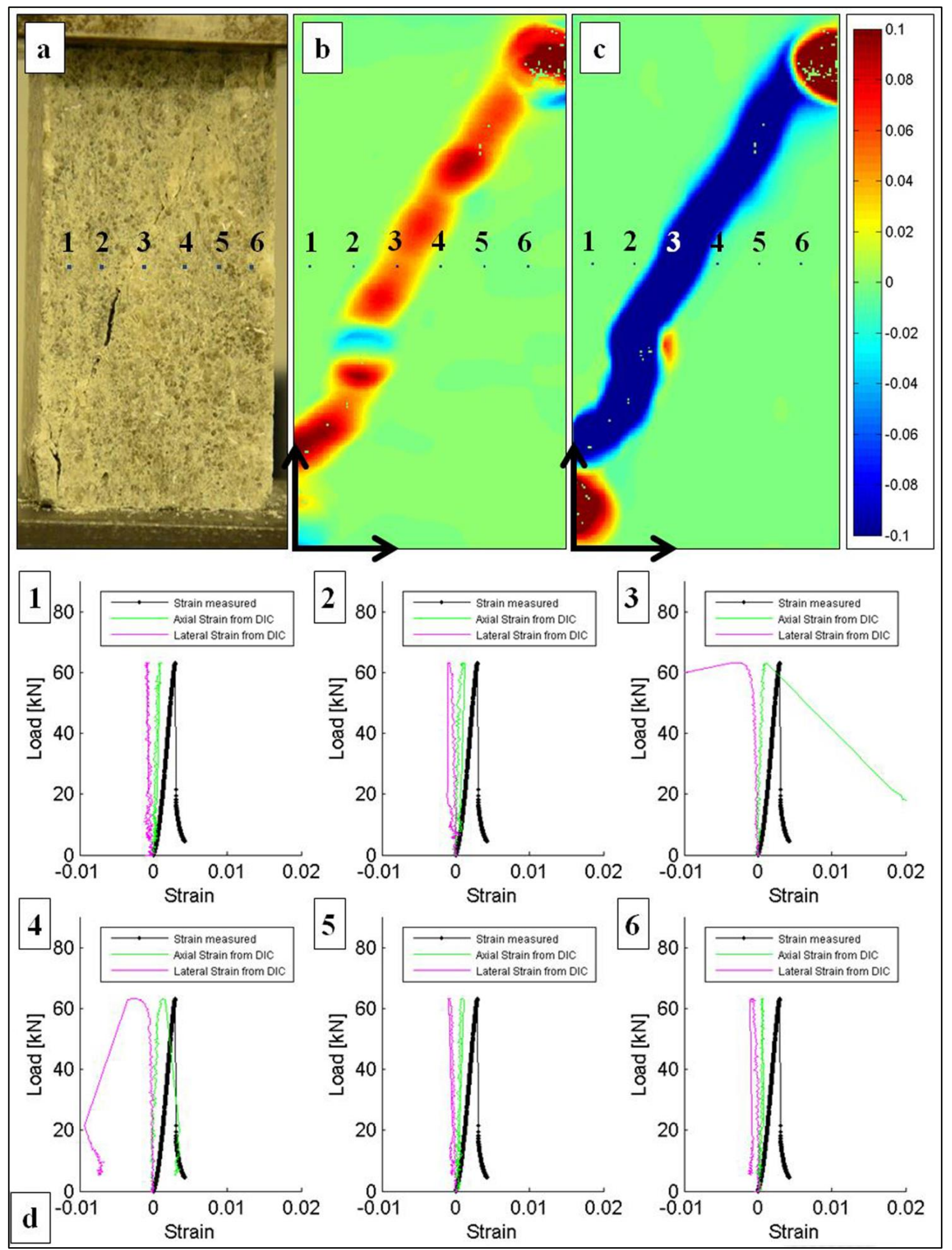

Figure 8 Sample 5 after the test. b. Map of axial strain at the end of the test. c. Map of lateral strain at the end of the test. d. Comparison of the load-strain curve measured from the load system (black curve) and the axial and lateral strain curves obtained with the DIC analysis for the six points showed in $\mathrm{b}$ and $\mathrm{c}$. Black arrows in figures $\mathrm{b}$ and $\mathrm{c}$ indicate the versus of the positive displacements. 
Eventually, Figures 9 and 10 show the load-displacement curves of two perpendicular faces of sample 6 with and without the outcropping of the failure surface, respectively. Graphs in Figure 9 do not show particular differences and perturbation until the loss of load that brings to the failure. On the other side, graphs in Figure 10 show a differentiation just after the peak, suggesting the formation of an incipient failure surface: points 5 and 6 move to the right, suggesting the opening of tensional cracks, and points 2, 3 and 4 move downward, following an initial sliding movement along the surface. The position of this incipient surface is evident from the displacement maps in figure $10 \mathrm{~b}$ and 10c. The following part of the curves are parallel among the different graphs, confirming that this face moved uniformly during the sample failure, which indeed happened on the orthogonal face (Fig. 9). Face in Fig. 10, being on the right of face in Fig. 9, is almost entirely under the fracture. Its axial movement, therefore, continues upward, following the movement of the piston, accommodating the sliding along the failure surface. 


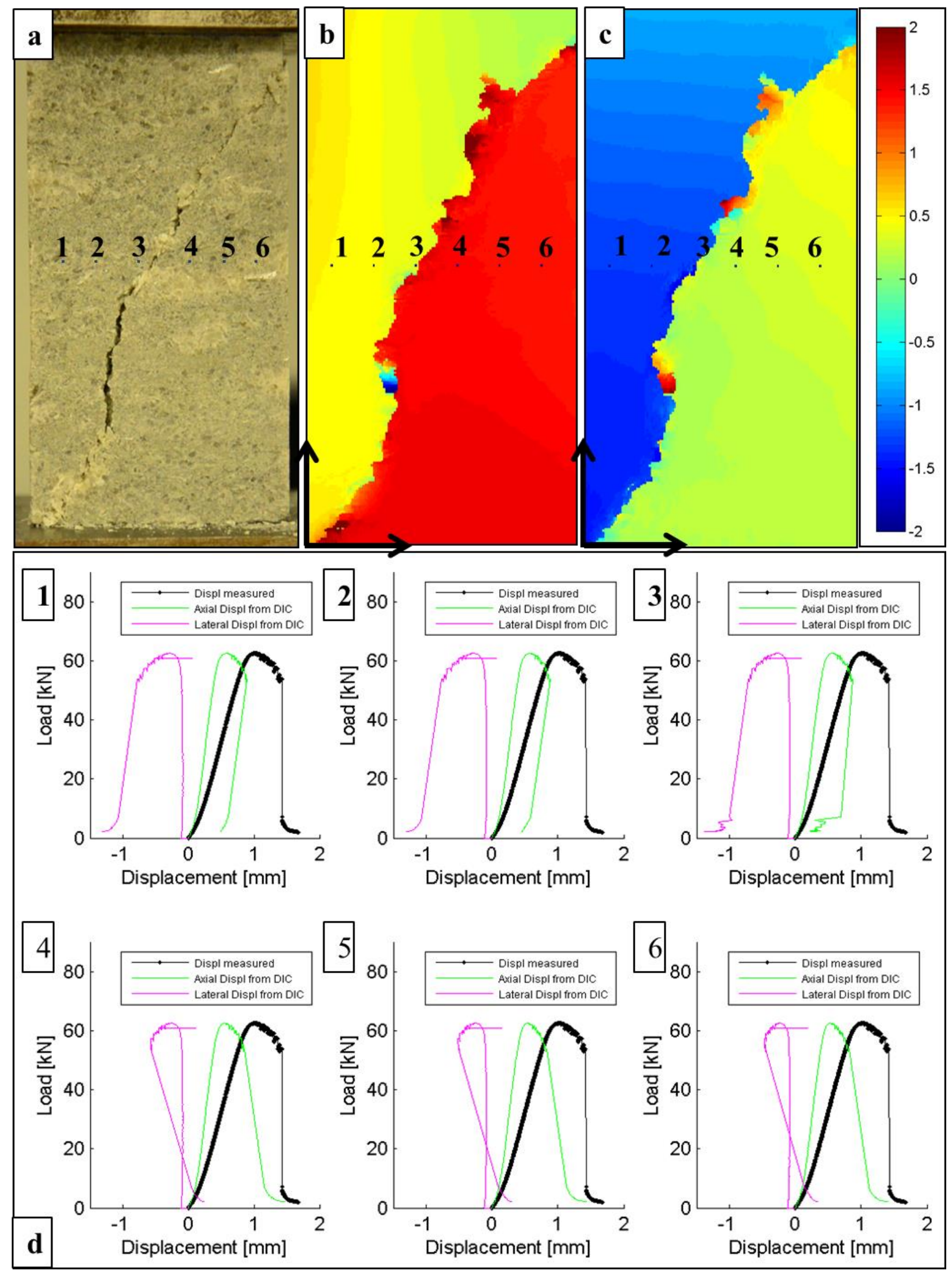

Figure 9 a. Face with the outcropping failure surface of sample 6 after the test. b. Map of axial displacement at the end of the test. c. Map of lateral displacement at the end of the test. d. Comparison of the load-displacement curve measured from the load system (black curve) and the axial and lateral displacement curves obtained with the DIC analysis for the six points showed in b and c. Black arrows in figures $\mathrm{b}$ and $\mathrm{c}$ indicate the versus of the positive displacements. 


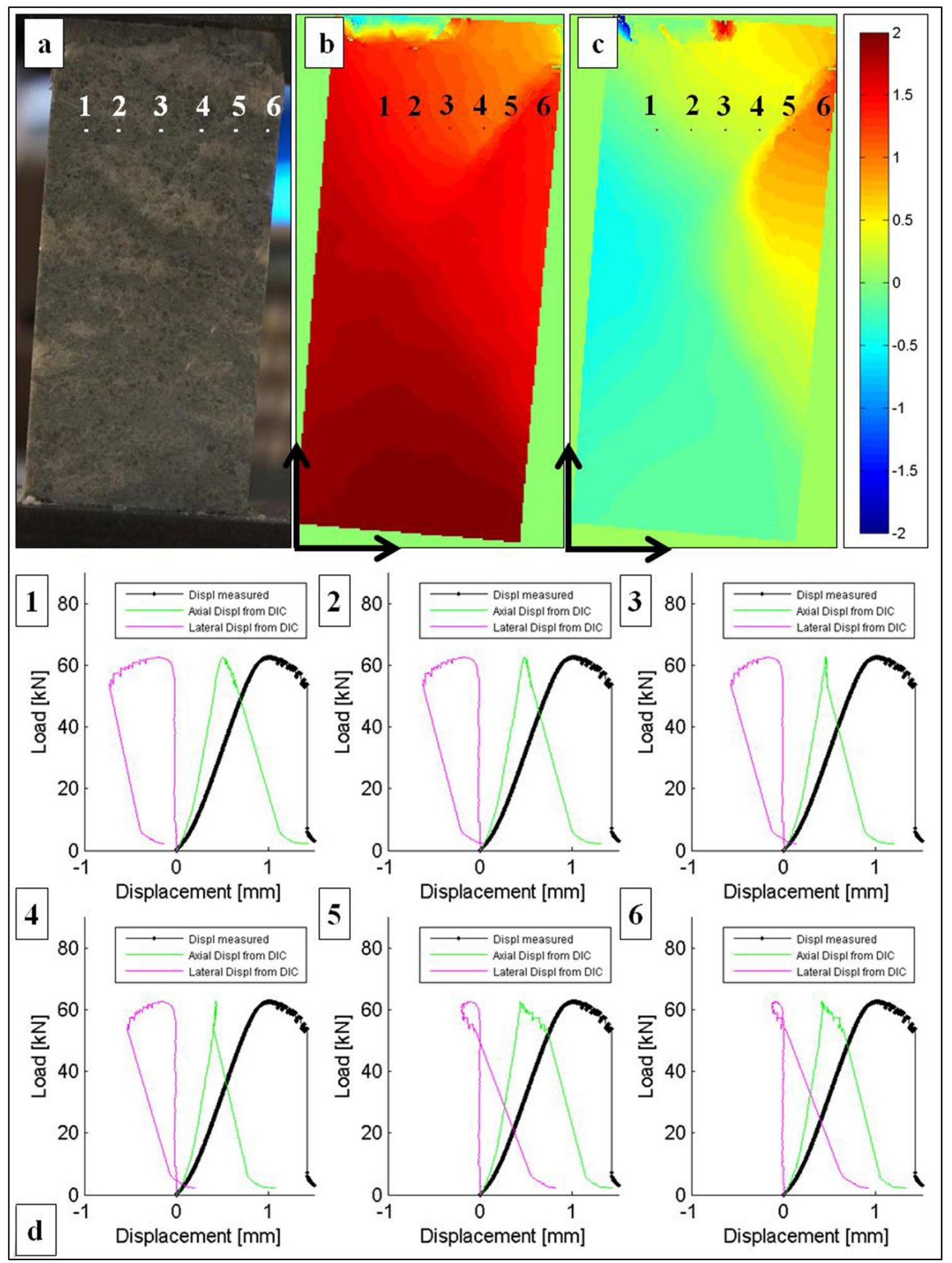

Figure 10 Face without the outcropping failure surface of sample 6 after the test. b. Map of axial displacement at the end of the test. c. Map of lateral displacement at the end of the test. d. Comparison of the load-displacement curve measured from the load system (black curve) and the axial and lateral displacement curves obtained with the DIC analysis for the six points showed in b and c. Black arrows in figures $\mathrm{b}$ and $\mathrm{c}$ indicate the versus of the positive displacements. 


\section{Conclusions}

DIC analysis confirmed to be a suitable method in the study of rock deformative features. The possibility to have pointwise measures of local strain on a grid that cover the entire sample surface offers a more complete dataset then any hardware method (e.g. electrical strain gauges, chain circumferential extensometers, LVDT transducers,...), without the incurrence of mechanical problems (e.g. breakage or wear of the tools). Moreover, the high acquisition frame rate assures the possibility to increase, if necessary, the time resolution of the analysis on a specific time interval. A difficulty can be found in the synchronization and combination of data from two different measurement tools (i.e. computer and camera, if not controlled from the computer itself).

We evaluated the possibility to apply this kind of methodology to a material with anomalous mechanical properties (i.e. gypsum). Results showed good repeatability and consistency. Similar displacement and strain fields were obtained for the 7 tested samples; differences may be explained in consideration of the different anisotropy orientations. Ncorr open source software proved to be a versatile, powerful and user-friendly tool for the elaboration of a large number of digital images, providing complete and reliable data.

Future studies will involve the application of the proposed methodology to understand the influence of textural and structural features of gypsum rocks on the mechanical answer.

\section{Acknowledgments}

The Authors desire to thank Professor Daniele Costanzo for the useful discussions and advice and the Geotechnical Laboratory of the Department of Structural, Geotechnical and Building Engineering of the Polytechnic of Turin.

\section{References}

Blaber J, Adair B, Antoniou A (2015). Ncorr: Open-Source 2D Digital Image Correlation Matlab Software. Experimental Mechanics 55(6):1105-1122. doi.org/10.1007/s11340-015-0009-1

Bobet A, Einstein HH (1998). Fracture coalescence in rock-type materials under uniaxial and biaxial compression. Int J Rock Mech Min Sci 35(7):863-888. doi.org/10.1016/S01489062(98)00005-9

Chu T, Ranson W, Sutton M (1985). Applications of digital-image-correlation techniques to experimental mechanics. Exp Mech 25(3):232-244. doi.org/10.1007/BF02325092

Dela Pierre F, Bernardi E, Cavagna S, Clari P, Gennari R, Irace A, Lozar F (2011) The Record of the Messinian Salinity Crisis in the Tertiary Piedmont Basin (NW Italy): The Alba Section Revisited. Palaeogeography, Palaeoclimatology, Palaeoecology 310 (3-4):238-55. doi.org/10.1016/j.palaeo.2011.07.017

Ferrero AM, Migliazza MR (2009). Theoretical and numerical study on uniaxial compressive behaviour of marl. Mechanics of Materials 41:561-572. doi.org/10.1016/j.mechmat.2009.01.011

Guy N, Seyedi DM, Hild F (2018). Characterizing Fracturing of Clay-Rich Lower Watrous Rock: From Laboratory Experiments to Nonlocal Damage-Based Simulations. Rock Mech Rock Eng 51, 1777-1787. doi.org/10.1007/s00603-018-1432-2 
Lugli S, Manzi V, Roveri M, Schreiber BC. (2010) The Primary Lower Gypsum in the Mediterranean: A New Facies Interpretation for the First Stage of the Messinian Salinity Crisis. Palaeogeography, Palaeoclimatology, Palaeoecology 297(1):83-99. doi.org/10.1016/j.palaeo.2010.07.017

Nguyen TL, Hall SA, Vacher P, Viggiani G (2011). Fracture mechanisms in soft rock: Identification and quantification of evolving displacement discontinuities by extended digital image correlation. Tectonophysics 503:117-128. doi.org/10.1016/j.tecto.2010.09.024

Pan B, Asundi A, Xie H, Gao J (2009). Digital image correlation using iterative least squares and pointwise least squares for displacement field and strain field measurements. Optics and Lasers in Engineering 47:865-874. doi.org/10.1016/j.optlaseng.2008.10.014

Peters W, Ranson W (1982). Digital imaging techniques in experimental stress analysis. Opt Eng 21(3):213427. doi.org/10.1117/12.7972925

Roveri M, Lugli S, Manzi V, Schreiber BC (2008). The Messinian Sicilian Stratigraphy Revisited: New Insights for the Messinian Salinity Crisis. Terra Nova 20(6): 483-88. doi.org/10.1111/j.13653121.2008.00842.x

Sagong M, Bobet A (2002). Coalescence of multiple flaws in a rock-model material in uniaxial compression. Int J Rock Mech Min Sci 39:229-241. doi.org/10.1016/S1365-1609(02)00027-8

Stirling RA, Simpson DJ, Davie CT (2013). The application of digital image correlation to Brazilian testing of sandstone. International Journal of Rock Mechanics \& Mining Sciences 60:111. doi.org/10.1016/j.ijrmms.2012.12.026

Vendroux G, Knauss W (1998). Submicron deformation field measurements: Part 2. Improved digital image correlation. Exp Mech 38(2):86-92. doi.org/10.1007/BF02321649

Wong LNY, Einstein HH (2009). Crack Coalescence in Molded Gypsum and Carrara Marble: Part 1. Macroscopic Observations and Interpretation. Rock Mech Rock Eng 42:475-511. doi.org/10.1007/s00603-008-0002-4

Yang G, Cai Z, Zhang X, Fu D (2015). An experimental investigation on the damage of granite under uniaxial tension by using a digital image correlation method. Optics and Lasers in Engineering 73: 46-52. doi.org/10.1016/j.optlaseng.2015.04.004

Zhang H, Huang G, Song H, Kang Y (2012). Experimental investigation of deformation and failure mechanisms in rock under indentation by digital image correlation. Engineering Fracture Mechanics 96: 667-675. doi.org/10.1016/j.engfracmech.2012.09.012 